\title{
Social Participation and Functional Decline: A Comparative Study of Rural and Urban Older People, Using Japan Gerontological Evaluation Study Longitudinal Data
}

\author{
Kazushige Ide ${ }^{1,2, *}$, Taishi Tsuji ${ }^{3} \oplus$, Satoru Kanamori ${ }^{4,5}$, Seungwon Jeong ${ }^{6}$, \\ Yuiko Nagamine ${ }^{3,7}$ (D) and Katsunori Kondo ${ }^{2,3,8}$ \\ 1 Department of Community General Support, Hasegawa Hospital, Yachimata, Chiba 289-1113, Japan \\ 2 Department of Public Health, Graduate School of Medicine, Chiba University, Chuo-ku, Chiba 260-8670, \\ Japan; kkondo@chiba-u.jp \\ 3 Department of Social Preventive Medical Sciences, Center for Preventive Medical Sciences, Chiba University, \\ Chuo-ku, Chiba 260-8670, Japan; tsuji.t@chiba-u.jp (T.T.); yuiko.mail@gmail.com (Y.N.) \\ 4 School of Nursing, Tokyo Women's Medical University, Shinjuku-ku, Tokyo 162-8666, Japan; \\ kanamori.satoru@twmu.ac.jp \\ 5 Department of Preventive Medicine and Public Health, Tokyo Medical University, Shinjuku-ku, \\ Tokyo 160-8402, Japan \\ 6 Department of Community Welfare, Faculty of Health Sciences, Niimi University, Nishigata Niimi, \\ Okayama 718-8585, Japan; k-jeong@niimi-u.ac.jp \\ 7 Department of Family Medicine, Graduate School of Medical and Dental Sciences, Tokyo Medical and \\ Dental University, Bunkyo-ku, Tokyo 113-8510, Japan \\ 8 Department of Geriatric Evaluation, Center for Gerontology and Social Science, National Center for \\ Geriatrics and Gerontology, Obu, Aichi 474-8511, Japan \\ * Correspondence: idex_waka@yahoo.co.jp; Tel.: +81-43-444-0137
}

Received: 14 December 2019; Accepted: 15 January 2020; Published: 18 January 2020

\begin{abstract}
This study compared the relationship between social participation, including work, and incidence of functional decline in rural and urban older people in Japan, by focusing on the number and types of organizations older people participated in. The longitudinal data of the Japan Gerontological Evaluation Study (JAGES) that followed 55,243 individuals aged 65 years or older for six years were used. The Cox proportional hazards model was employed to calculate the hazard ratio (HR) of the incidence of functional decline over six years and the stratification of rural and urban settings. In this model, we adjusted 13 variables as behavioral, psychosocial, and functional confounders. The more rural and urban older people participated in various organizations, the more they were protected from functional decline. Participation in sports (HR: rural $=0.79$; urban $=0.83$ ), hobby groups (HR: rural $=0.76$; urban $=0.90)$, and work (HR: rural $=0.83$; urban $=0.80$ ) significantly protected against the incidence of decline in both rural and urban areas. For both rural and urban older people, promoting social participation, such as sports and hobby groups and employment support, seemed to be an important aspect of public health policies that would prevent functional decline.
\end{abstract}

Keywords: social participation; work; functional decline; rural; urban

\section{Introduction}

A strategy of active ageing [1], by linking the key policy domains of employment, pension, retirement, health, and citizenship, provides a sound basis to respond to the challenges presented by population ageing [2]. In recent times, the practical challenge has been to open up the innovative policy 
spaces that might make active ageing not only thinkable but also achievable [3]. In European countries, the Active Aging Index (AAI) tool measures the untapped potential of older people for active and healthy aging across countries [4]. The AAI consists of four domains: employment, participation in society; independent, healthy, and secure living; and capacity and enabling environment for active ageing $[4,5]$.

The social participation of older people, one of the domains of AAI [4,5], is a key factor of "successful aging" [6] and an important element of "active aging" [7]. Social participation is one of the core indicators of "age-friendly cities" proposed by the World Health Organization in recent years [8]. When considering public health services in a rapidly aging society, social participation is highlighted as a modifiable target of health interventions.

In many longitudinal studies, social participation has been reported as effective for health outcomes such as functional disability [9-13], cognitive disability [14-16], instrumental activities of daily living decline [17-19], and basic activities of daily living decline [20]. Among them, some studies focused on the number and types of organizations in which older people participated [10,13,16-18]. These studies suggested that older people who participate in more organizations are healthier than those who do not participate, and that the relationships between social participation and health varied according to the types of organization they participate in.

However, these studies $[10,13,16-18]$ do not consider two issues. First, these studies do not consider "work" as a kind of social participation. According to the Organization for Economic Co-Operation and Development (OECD) scoreboard for older workers, older workers aged 65-69 years increased from $20.3 \%$ to $25.5 \%$ between 2006 and 2016 and from $12.0 \%$ to $14.6 \%$ at age $70-74$ years during the same period, in OECD member countries [21]. However, recommendations made by the Council on Aging and Employment Policies [22] encourage supporting the employment of older people. In AAI, work and social participation are separate domains, but these are also defined as the actual experience of active aging $[4,5]$. Considering these circumstances, it is necessary to include work in social participation in the analysis of the number and types of organizations in which older people participated. Second, these studies do not consider residential environments, such as rural and urban areas. Generally, older people living in rural areas suffer with more depression [23], lower levels of basic activities of daily living [20], and a higher risk of developing disability [24] compared to those living in urban areas. In addition, the life expectancy is shorter in rural areas, and the difference between urban and rural areas is widening [25]. Previous studies [13,26] showed that rural older people were less socially active than urban older people. However, previous studies state that bonding social capital comprising a connection between community members is often stronger among rural older adults, resulting in community strength $[27,28]$. In addition, environmental factors such as neighborhood socioeconomic status and access to services and transportation differ in rural and urban areas [29]. Furthermore, the relationship between social participation and health outcomes, such as depression [23] and self-rated health [26,30], also differs. These may be the reasons why rural older people are unhealthier than urban older people. The relationship between social participation and functional decline may differ between rural and urban areas; however, such a relationship has not been clarified.

Thus, we aimed at clarifying whether there were differences between rural and urban areas in the relationship between social participation, including work, and incidence of functional decline. This study was conducted to inform public health policies that could prevent the need for long-term care of older individuals residing in rural and urban areas, which have different environmental factors.

\section{Materials and Methods}

\subsection{Data}

We used longitudinal data from the Japan Gerontological Evaluation Study (JAGES). JAGES is one of the few population-based gerontological repeated surveys in Japan focused on the social 
determinants of health and the social environment [31,32]. From August 2010 to January 2012, self-reported questionnaires were mailed to 95,827 community-dwelling independent individuals aged 65 years and older who were not eligible to receive benefits from public long-term care insurance services. They were randomly selected from 13 municipalities, including rural and urban areas. Overall, 62,418 people participated (response rate, $65.1 \%$ ) in the survey called JAGES2010. They were followed up for about six years (minimum 5.2 years; maximum 6.4 years). Of the total respondents (response rate $65.1 \%), 54,539(87.4 \%)$ were successfully linked to the incident records of long-term care insurance certification. We excluded 7223 responses for the following reasons: (i) missing information on address $(n=101)$ and activities of daily living (ADL) $(n=1482)$; and (ii) having physical or cognitive disabilities reported in their questionnaires $(n=988)$. Moreover, 4662 respondents in long-term care within two years were removed to avoid the possibility of reverse causality (i.e., the possibility that people who were at high risk of functional decline did not participate socially). The final number of participants in this analysis was 47,306 .

Ethical approval for the study was obtained from the Nihon Fukushi University Ethics Committee (application number: 10-05), the National Center for Geriatrics and Gerontology (application number: No. 992-2), and Chiba University Ethics Committee (application number: No. 2493).

\subsection{Dependent Variable}

The dependent variable was the incidence of functional decline during the follow-up period. The incidence of functional decline was defined by medical certification for Long-Term Care Insurance. Certification of decline is based on the formal evaluation of the need for Long-Term Care according to uniform criteria applied throughout Japan, and comprises both a home-visit interview, as well as the written opinion of a primary physician [33]. This formal evaluation is based on a standardized multistep assessment of functional and cognitive impairments [33]. We obtained information on the certification of long-term needs, death, and moving out of the study area, from the long-term care insurance database maintained by the municipalities. These criteria for determining the onset of functional decline have been used in previous epidemiological studies [4-6].

\subsection{Independent Variable}

The independent variable was social participation. With reference to previous research [5], social participation was classified into the following six types: neighborhood groups (local community), hobby groups (hobby), sports groups or clubs (sports), industrial groups (industry), volunteer groups (volunteer), and senior citizen clubs (citizen). Furthermore, we considered work (work) as a form of social participation and therefore analyzed seven types of organizations in this study.

Participation in organizations other than work was assessed by using the following question: "How often do you participate in the following clubs or groups?". Participants were given the following choices: "almost every day", "twice or thrice a week", "once a week", "once or twice a month", "a few times a year" and "never". The response was categorized as "yes" if individuals selected any of the five options from "a few times a year" to "almost every day", and "no" if they selected "never". Participation in work was assessed by using the following question: "What is your current working status?". Participants were given the following choices: "working", "retired and not working now" and "never had a job". The response was categorized as "yes" if the participants answered "working", and "no" if they answered "retired and not working now" or "never got a job".

The total number of types of organizations each participant participated in was tallied, and participation was categorized as 0 (no participation), 1,2 , or $\geq 3$ organizations, or "missing". If the response to participation in all organizations was missing, we deemed it as "missing" category in this analysis. The organizations particularly unique to Japan among the types named above are senior citizen clubs. Japan's senior citizens clubs conduct a wide range of activities, including group activities such as sports, hobbies, cultural activities, and performing arts. 


\subsection{Covariates}

Based on a previous study [10], sex, age, annual equivalized income, educational attainment, marital status, and self-reported medical conditions were considered potential confounding factors that may correlate with social participation and incidence of functional disability. In addition, behavioral, psychosocial, and physiological factors were also used as covariates and potential mechanisms influencing health and social participation. Smoking, alcohol consumption, daily walking time, and frequency of going outdoors were assessed as behavioral factors. Depression (Geriatric Depression Scale), emotional support, instrumental support, and frequency of meeting friends were assessed as psychosocial factors. Instrumental activity of daily living (IADL) was assessed as a functional factor. All variables were categorized as shown in Table 1 and set as dummy variables. A "missing" category was used in the analysis to account for missing responses to questions.

\subsection{Classification of Rural and Urban Settings}

The definition of functional urban areas from the OECD metropolitan database [34] was used to classify rural and urban settings. The definition of urban areas in OECD countries uses population density to identify urban cores, and travel-to-work flows to identify the hinterlands whose labor market is highly integrated with the cores. The methodology consisted of the three following main steps: (1) identification of core municipalities through gridded population data; (2) connecting noncontiguous cores belonging to the same functional urban area; and (3) identification of urban hinterlands. This methodology makes it possible to compare functional urban areas of similar size across different countries and classifies functional urban areas according to population size into the following four types: (1) small urban areas (with a population below 200,000 people); (2) medium-sized urban areas (with a population between 200,000 and 500,000); (3) metropolitan areas (with a population between 500,000 and 1.5 million); and (4) large metropolitan areas (with a population of 1.5 million or more). From the OECD's four functional urban areas, all cities, including metropolitan and large metropolitan areas, were designated urban areas in this study, and all others were designated rural areas. In this study, eight municipalities were designated as rural, and five municipalities were designated as cities.

\subsection{Statistical Analysis}

First, we conducted a chi-square test to compare variables between rural and urban males and females. As the sample size in this study is very large, we calculated Cramer's V as the effect size in addition to the $p$-value. The criteria for Cramer's V are 0.1 for small, 0.3 for medium, and 0.5 for large. Second, the Cox proportional hazards model was employed to calculate the hazard ratios (HRs) and $95 \%$ confidence intervals (CI) of the incidence of functional decline over six years, stratified by rural, and urban settings. In each model, nonparticipation in an organization was set as the referent category. In the analysis of the number or types of organization older people participate in, we conducted a trend test. Further, six types of social participation were introduced in each model separately. The following two models of analysis were used: a regression analysis was performed with simultaneous forced entry of sex, age, equivalent income, educational attainment, marital status, and self-reported medical conditions as covariates (Model 1). Model 2 added the following confounding factors to Model 1: smoking, alcohol consumption, walking time, frequency of going outdoors, Geriatric Depression Scale, emotional support, instrumental support, frequency of meeting friends, and IADL. Finally, to confirm the robustness of our finding, we performed a complete case analysis, excluding patients missing any of the variables used in the analysis. STATA V.15 (Stata Corp, College Station, TX, USA) was used to conduct a statistical analysis, with a significance level of $5 \%$. 
Table 1. Baseline characteristics of respondents (2010-2012).

\begin{tabular}{|c|c|c|c|c|c|c|}
\hline & \multirow[t]{2}{*}{ Variables } & \multicolumn{2}{|c|}{$\begin{array}{c}\text { Rural } \\
(n=15,083)\end{array}$} & \multicolumn{2}{|c|}{$\begin{array}{c}\text { Urban } \\
(n=32,223)\end{array}$} & \multirow{2}{*}{$\begin{array}{c}p \text {-Value } \\
(\text { Cramer's V) }\end{array}$} \\
\hline & & $n$ & $\%$ & $n$ & $\%$ & \\
\hline \multirow{2}{*}{ Sex } & Male & 6758 & 44.8 & 15,163 & 47.0 & \multirow{2}{*}{$\begin{array}{c}<0.001 \\
(0.02)\end{array}$} \\
\hline & Female & 8325 & 55.2 & 17,063 & 53.0 & \\
\hline \multirow{5}{*}{$\begin{array}{l}\text { Age } \\
\text { (years) }\end{array}$} & $65-69$ & 4287 & 28.4 & 9676 & 30.0 & \multirow{5}{*}{$\begin{array}{c}<0.001 \\
(0.04)\end{array}$} \\
\hline & $70-74$ & 4536 & 30.1 & 10,343 & 32.1 & \\
\hline & $75-79$ & 3470 & 23.0 & 7257 & 22.5 & \\
\hline & $80-84$ & 1973 & 13.1 & 3611 & 11.2 & \\
\hline & $85+$ & 817 & 5.4 & 1336 & 4.2 & \\
\hline \multirow{4}{*}{$\begin{array}{l}\text { Equivalent income } \\
\text { (million yen) }\end{array}$} & Low $(<2.0)$ & 7127 & 47.3 & 11,815 & 36.7 & \multirow{4}{*}{$\begin{array}{c}<0.001 \\
(0.13)\end{array}$} \\
\hline & Middle (2.0-3.9) & 3988 & 26.4 & 11,321 & 35.1 & \\
\hline & $\operatorname{High}(\geq 4.0)$ & 939 & 6.2 & 3616 & 11.2 & \\
\hline & Missing & 3029 & 20.1 & 5471 & 17.0 & \\
\hline \multirow{4}{*}{$\begin{array}{c}\text { Educational } \\
\text { attainment } \\
\text { (years) }\end{array}$} & $<10$ & 8404 & 55.7 & 14,103 & 43.8 & \multirow{4}{*}{$\begin{array}{l}<0.001 \\
(0.12)\end{array}$} \\
\hline & $10-12$ & 4432 & 29.4 & 11,182 & 34.7 & \\
\hline & $\geq 13$ & 1853 & 12.3 & 6255 & 19.4 & \\
\hline & Missing & 394 & 2.6 & 683 & 2.1 & \\
\hline \multirow{3}{*}{ Marital status } & Married & 10,611 & 70.3 & 23,315 & 72.4 & \multirow{3}{*}{$\begin{array}{c}<0.001 \\
0.04\end{array}$} \\
\hline & Single & 4111 & 27.3 & 8480 & 26.3 & \\
\hline & Missing & 361 & 2.4 & 428 & 1.3 & \\
\hline \multirow{3}{*}{$\begin{array}{l}\text { Self-reported } \\
\text { medical } \\
\text { conditions }\end{array}$} & Illness & 10,267 & 68.1 & 21,859 & 67.8 & \multirow{3}{*}{$\begin{array}{l}0.243 \\
(0.01)\end{array}$} \\
\hline & No illness & 3508 & 23.2 & 7677 & 23.8 & \\
\hline & Missing & 1308 & 8.7 & 2687 & 8.4 & \\
\hline \multirow{4}{*}{ Smoking } & Never smoked & 8440 & 56.0 & 17,174 & 53.3 & \multirow{4}{*}{$\begin{array}{l}<0.001 \\
(0.04)\end{array}$} \\
\hline & Past smoker & 3566 & 23.6 & 8649 & 26.9 & \\
\hline & Current smoker & 1437 & 9.5 & 3330 & 10.3 & \\
\hline & Missing & 1640 & 10.9 & 3070 & 9.5 & \\
\hline \multirow{4}{*}{$\begin{array}{c}\text { Alcohol } \\
\text { consumption }\end{array}$} & Never drank & 9122 & 60.5 & 18,420 & 57.2 & \multirow{4}{*}{$\begin{array}{l}<0.001 \\
(0.03)\end{array}$} \\
\hline & Past drinker & 440 & 2.9 & 1021 & 3.2 & \\
\hline & Current drinker & 4684 & 31.1 & 10,836 & 33.6 & \\
\hline & Missing & 837 & 5.5 & 1946 & 6.0 & \\
\hline & $>90 \min$ & 2515 & 16.7 & 5004 & 15.5 & \\
\hline & $60-90 \mathrm{~min}$ & 2130 & 14.1 & 5029 & 15.6 & \\
\hline Walking time & $30-60 \mathrm{~min}$ & 4558 & 30.2 & 10,960 & 34.0 & $<0.001$ \\
\hline & $<30 \mathrm{~min}$ & 4905 & 32.5 & 9341 & 29.0 & \\
\hline & Missing & 975 & 6.5 & 1889 & 5.9 & \\
\hline & Almost everyday & 6607 & 43.8 & 18,496 & 57.4 & \\
\hline & 2-3 times/week & 4601 & 30.5 & 8288 & 25.7 & \\
\hline Frequency of & About once/week & 1755 & 11.6 & 2253 & 7.0 & $<0.001$ \\
\hline & Rarely & 1351 & 9.0 & 1384 & 4.3 & \\
\hline & Missing & 769 & 5.1 & 1802 & 5.6 & \\
\hline & No depression & 9313 & 61.8 & 19,977 & 62.0 & \\
\hline Donreccion & Depressive tendency & 2613 & 17.3 & 5343 & 16.6 & 0.002 \\
\hline Depression & Depression & 822 & 5.4 & 1595 & 4.9 & $(0.02)$ \\
\hline & Missing & 2335 & 15.5 & 5308 & 16.5 & \\
\hline & Available & 13,052 & 86.5 & 28,584 & 88.7 & \\
\hline $\begin{array}{l}\text { Emotional } \\
\text { supnort }\end{array}$ & Not available & 1209 & 8.0 & 2310 & 7.2 & $<0.001$ \\
\hline & Missing & 822 & 5.5 & 1329 & 4.1 & \\
\hline & Available & 12,369 & 82.0 & 26,971 & 83.7 & \\
\hline $\begin{array}{l}\text { support } \\
\text { sumstrumental }\end{array}$ & Not available & 1906 & 12.6 & 3906 & 12.1 & $<0.001$ \\
\hline & Missing & 808 & 5.4 & 1346 & 4.2 & \\
\hline
\end{tabular}


Table 1. Cont.

\begin{tabular}{|c|c|c|c|c|c|c|}
\hline & \multirow[t]{2}{*}{ Variables } & \multicolumn{2}{|c|}{$\begin{array}{c}\text { Rural } \\
(n=15,083)\end{array}$} & \multicolumn{2}{|c|}{$\begin{array}{c}\text { Urban } \\
(n=32,223)\end{array}$} & \multirow{2}{*}{$\begin{array}{c}p \text {-Value } \\
(\text { Cramer's V) }\end{array}$} \\
\hline & & $n$ & $\%$ & $n$ & $\%$ & \\
\hline \multirow{6}{*}{$\begin{array}{l}\text { Frequency of } \\
\text { meeting friends }\end{array}$} & Almost everyday & 2247 & 14.90 & 4347 & 13.5 & \multirow{6}{*}{$\begin{array}{c}<0.001 \\
(0.04)\end{array}$} \\
\hline & 2-3 times/week & 3513 & 23.30 & 7206 & 22.4 & \\
\hline & About once/week & 2461 & 16.30 & 5293 & 16.4 & \\
\hline & 1-2 times/month & 2914 & 19.30 & 6049 & 18.8 & \\
\hline & A few times a year or less & 2841 & 18.80 & 7251 & 22.5 & \\
\hline & Missing & 1107 & 7.40 & 2077 & 6.4 & \\
\hline \multirow{3}{*}{$\begin{array}{l}\text { Instrumental } \\
\text { activity of daily } \\
\text { living (IADL) }\end{array}$} & Not decline & 6073 & 40.3 & 12,578 & 39.0 & \multirow{3}{*}{$\begin{array}{l}0.025 \\
(0.01)\end{array}$} \\
\hline & Decline & 7230 & 47.9 & 15,856 & 49.2 & \\
\hline & Missing & 1780 & 11.8 & 3789 & 11.8 & \\
\hline \multirow{5}{*}{$\begin{array}{l}\text { Number of types } \\
\text { of organizations }\end{array}$} & 0 & 3187 & 21.1 & 7700 & 23.9 & \multirow{5}{*}{$\begin{array}{c}<0.001 \\
(0.06)\end{array}$} \\
\hline & 1 & 3420 & 22.7 & 7964 & 24.7 & \\
\hline & 2 & 2691 & 17.8 & 6173 & 19.1 & \\
\hline & $\geq 3$ & 5227 & 34.7 & 9588 & 29.8 & \\
\hline & Missing & 558 & 3.7 & 798 & 2.5 & \\
\hline \multicolumn{7}{|c|}{ Type of social participation } \\
\hline \multirow{3}{*}{ Local community } & Nonparticipation & 5909 & 39.2 & 14,781 & 45.9 & \multirow{3}{*}{$\begin{array}{c}<0.001 \\
(0.07)\end{array}$} \\
\hline & Participation & 5886 & 39.0 & 10,802 & 33.5 & \\
\hline & Missing & 3288 & 21.8 & 6640 & 20.6 & \\
\hline \multirow{3}{*}{ Hobby } & Nonparticipation & 6656 & 44.1 & 13,411 & 41.6 & \multirow{3}{*}{$\begin{array}{c}<0.001 \\
(0.05)\end{array}$} \\
\hline & Participation & 5430 & 36.0 & 13,212 & 41.0 & \\
\hline & Missing & 2997 & 19.9 & 5600 & 17.4 & \\
\hline \multirow{3}{*}{ Sports } & Nonparticipation & 8540 & 56.6 & 18,242 & 56.6 & \multirow{3}{*}{$\begin{array}{l}0.001 \\
(0.02)\end{array}$} \\
\hline & Participation & 3272 & 21.7 & 7375 & 22.9 & \\
\hline & Missing & 3271 & 21.7 & 6606 & 20.5 & \\
\hline \multirow{3}{*}{ Industry } & Nonparticipation & 8791 & 58.3 & 19,293 & 59.9 & \multirow{3}{*}{$\begin{array}{r}<0.001 \\
(0.04)\end{array}$} \\
\hline & Participation & 2020 & 13.4 & 4829 & 15.0 & \\
\hline & Missing & 4272 & 28.3 & 8101 & 25.1 & \\
\hline \multirow{3}{*}{ Volunteer } & Nonparticipation & 8787 & 58.3 & 19,803 & 61.5 & \multirow{3}{*}{$\begin{array}{l}<0.001 \\
(0.03)\end{array}$} \\
\hline & Participation & 2292 & 15.2 & 4526 & 14.0 & \\
\hline & Missing & 4004 & 26.5 & 7894 & 24.5 & \\
\hline \multirow{3}{*}{ Citizen } & Nonparticipation & 7842 & 52.0 & 19,244 & 59.7 & \multirow{3}{*}{$\begin{array}{c}<0.001 \\
(0.10)\end{array}$} \\
\hline & Participation & 4247 & 28.2 & 6165 & 19.1 & \\
\hline & Missing & 2994 & 19.8 & 6814 & 21.2 & \\
\hline \multirow{3}{*}{ Work } & Nonparticipation & 9002 & 59.7 & 21,572 & 67.0 & \multirow{3}{*}{$\begin{array}{c}<0.001 \\
(0.10)\end{array}$} \\
\hline & Participation & 3397 & 22.5 & 7166 & 22.2 & \\
\hline & Missing & 2684 & 17.8 & 3485 & 10.8 & \\
\hline
\end{tabular}

\section{Results}

Table 1 presents the descriptive statistics of rural and urban variables. Of the 47,306 respondents included in the analyses, 21,921 were male and 25,385 were female. Of the 21,921 males, 6758 lived in rural and 15,163 lived in urban settings. Of the 25,385 females, 8375 lived in rural and 17,060 lived in urban settings. The average age of the rural and urban older people was 73.8 (standard deviation (SD), 5.9) and 73.3 (SD, 5.6) years, respectively. Of the respondents in rural and urban areas, $2399(15.9 \%)$ and $4018(15.3 \%)$ reported functional decline, respectively. The average tracking period was 2028.1 days $(\mathrm{SD}=364.1)$ for rural and 1951.8 days $(\mathrm{SD}=361.7)$ for urban older peoples. The comparison of variables across rural and urban areas revealed that there were many urban-rural differences. However, the sample size for this study was so large that even minor differences could result in statistical differences. In fact, Cramer's V in the chi-square test between almost all variables was judged to be very small, and the realistic effect size was small. However, describing the difference 
between rural areas and cities when the effect size is 0.1 or more indicated that older people in rural areas had a lower equivalent income $(p<0.001)$, lower educational attainment $(p<0.001)$, and went outdoors less frequently $(p<0.001)$ than those in urban areas. Although the effect size was small, the distribution of the number of organizations in which older people participated differed between rural and urban areas $(p<0.001)$. When types of social participation were analyzed, rural older people participated a lot more in senior citizen clubs $(p<0.001)$ than urban older people. The distribution of participation in work differed between rural and urban areas ( $p<0.001$; Cramer's V $=0.1)$; it was thought to be due to the missing category.

Table 2 presents the results of a Cox proportional hazards model analysis of the different types of organizations and incidence of functional decline. In the crude model and Model 1, a "dose-response" relationship was seen both among rural and urban areas, with progressively lower HRs as the number of different types of organizations increased. In Model 2 for rural older people, the HRs were 0.94 (95\% CI: 0.84-1.05) for participation in one, 0.85 (0.75-0.97) for participation in two, and $0.76(0.67-0.86)$ for participation in three or more different types of organizations, with the significant difference disappearing only for participation in one type of organization. For urban older people, the HRs were 0.92 (95\% CI: 0.85-0.99) for participation in one, 0.87 (0.80-0.96) for participation in two, and $0.82(0.75-0.89)$ for participation in three or more different types of organizations, with the statistical significance for one or more different types of organizations. In other words, older people in urban areas were protected from functional decline through one type of participation. On the other hand, older people in rural areas required more than one type of participation, but older people in rural areas had lower HRs when participating in more than two types of organizations than older people in urban areas.

Table 2. HRs for participation in one, two, and three or more different types of organizations.

\begin{tabular}{cccc}
\hline \multirow{2}{*}{ Rural } & Crude Model & Model 1 & Model 2 \\
\cline { 2 - 4 } & HR (95\% CI) & HR (95\% CI) & HR (95\% CI) \\
\hline 0 & 1.00 Ref & 1.00 Ref & 1.00 Ref \\
1 & $0.71^{*}(0.64-0.79)$ & $0.87^{*}(0.78-0.97)$ & $0.94(0.84-1.05)$ \\
2 & $0.57^{*}(0.50-0.64)$ & $0.75 *(0.66-0.85)$ & $0.85 *(0.75-0.97)$ \\
$\geq 3$ & $0.43 *(0.39-0.49)$ & $0.62 *(0.56-0.70)$ & $0.76 *(0.67-0.86)$ \\
Trend $p$ & $p<0.05$ & $p<0.05$ & $p<0.05$ \\
\hline Urban & Crude model & Model 1 & Model 2 \\
\cline { 2 - 4 } & HR (95\% CI) & HR (95\% CI) & HR (95\% CI) \\
\hline 0 & 1.00 Ref & 1.00 Ref & 1.00 Ref \\
1 & $0.69 *(0.64-0.75)$ & $0.85 *(0.79-0.91)$ & $0.92 *(0.85-0.99)$ \\
2 & $0.59 *(0.55-0.65)$ & $0.77 *(0.71-0.84)$ & $0.87 *(0.80-0.96)$ \\
$\geq 3$ & $0.48 *(0.44-0.52)$ & $0.67 *(0.62-0.72)$ & $0.82 *(0.75-0.89)$ \\
Trend $p$ & $p<0.05$ & $p<0.05$ & $p<0.05$ \\
\hline
\end{tabular}

HR: Hazard ratio; CI: confidence interval; Ref: reference. ${ }^{*} p<0.05$. Model 1: Crude model + sex, age, equivalent income, educational attainment, marital status, and self-reported medical conditions. Model 2: Model $1+$ smoking, alcohol consumption, walking time (per day), frequency of going outdoors, depression, emotional support, instrumental support, frequency of meeting friends, and IADL.

The results of the complete case analysis are shown in Table S1. The results of the complete case analysis, excluding patients missing any of the variables used in the analysis were similar to those when the "missing" category was used in the analysis to account for missing responses to questions. The full modeling results in Model 2 were presented in Table S2. In this study, Model 2 added social networks such as emotional support, instrumental support, and frequency of meeting friends. Rural and urban older people who could not avail emotional support were not protective against functional decline compared with those who could avail it. Furthermore, urban older people who could not avail instrumental support were not protective against functional decline compared with those who could 
avail it, but this was not the case in rural areas. The frequency of meeting friends was not statistically significant in rural and urban areas.

Table 3 presents the results of the Cox proportional hazards model analysis of the type of social participation and incidence of functional decline. Almost all types of organizational participation were strongly protective against functional decline, but senior citizen clubs had the opposite relationship in the crude model. Similarly, many types of organizational participation were protective against functional decline in Model 1. In Model 2 for rural older people, participation in hobbies (HR $=0.76$; 95\% CI: 0.68-0.85), sports (HR $=0.79 ; 95 \%$ CI: 0.69-0.89), work (HR $=0.83 ; 95 \%$ CI: $0.76-0.91)$, and local community ( $\mathrm{HR}=0.86 ; 95 \% \mathrm{CI}: 0.77-0.95)$ was found to be protective against the incidence of decline. For urban older people, participation in work (HR $=0.80 ; 95 \% \mathrm{CI}: 0.70-0.91)$, sports (HR = 0.83 ; 95\% CI: 0.77-0.91), and hobbies (HR $=0.90 ; 95 \%$ CI: $0.84-0.97$ ) was found to be protective against the incidence of decline.

Table 3. HRs for type of social participation (reference: nonparticipation in each organization).

\begin{tabular}{cccc}
\hline \multirow{2}{*}{ Rural } & Crude Model & Model 1 & Model 2 \\
\cline { 2 - 4 } & HR (95\% CI) & HR (95\% CI) & HR (95\% CI) \\
\hline Local Community & $0.59 *(0.54-0.65)$ & $0.77 *(0.70-0.86)$ & $0.86 *(0.77-0.95)$ \\
Hobby & $0.57 *(0.52-0.64)$ & $0.61 *(0.60-0.75)$ & $0.76 *(0.68-0.85)$ \\
Sports & $0.62 *(0.55-0.70)$ & $0.70 *(0.62-0.78)$ & $0.79 *(0.69-0.89)$ \\
Industry & $0.67 *(0.58-0.78)$ & $0.92(0.84-1.01)$ & $1.01(0.87-1.18)$ \\
Volunteer & $0.62 *(0.54-0.72)$ & $0.77 *(0.67-0.89)$ & $0.89(0.77-1.03)$ \\
Citizen & $1.40 *(1.27-1.54)$ & $0.94(0.85-1.03)$ & $1.02(0.93-1.13)$ \\
Work & $0.48 *(0.42-0.54)$ & $0.74 *(0.65-0.84)$ & $0.83 *(0.76-0.91)$ \\
\hline Urban & Crude Model & Model 1 & Model 2 \\
\cline { 2 - 4 } & HR (95\% CI) & HR (95\% CI) & HR (95\% CI) \\
\hline Local Community & $0.70 *(0.65-0.75)$ & $0.84 *(0.79-0.90)$ & $0.95(0.88-1.01)$ \\
Hobby & $0.70 *(0.66-0.75)$ & $0.78 *(0.73-0.84)$ & $0.90 *(0.84-0.97)$ \\
Sports & $0.60 *(0.55-0.65)$ & $0.73 *(0.67-0.79)$ & $0.83 *(0.77-0.91)$ \\
Industry & $0.81 *(0.74-0.89)$ & $0.90(0.78-1.05)$ & $1.04(0.95-1.15)$ \\
Volunteer & $0.66 *(0.60-0.73)$ & $0.80 *(0.73-0.89)$ & $0.94(0.85-1.04)$ \\
Citizen & $1.37 *(1.28-1.47)$ & $0.89 *(0.83-0.96)$ & $0.99(0.92-1.07)$ \\
Work & $0.50 *(0.46-0.55)$ & $0.80 *(0.73-0.87)$ & $0.80 *(0.70-0.91)$ \\
\hline
\end{tabular}

HR: Hazard ratio; CI: confidence interval; Ref: reference. ${ }^{*} p<0.05$. Model 1: Crude model + sex, age, equivalent income, educational attainment, marital status, and self-reported medical conditions. Model 2: Model $1+$ smoking, alcohol consumption, walking time (per day), frequency of going outdoors, depression, emotional support, instrumental support, frequency of meeting friends, and IADL.

The results of the complete case analysis are shown in Table S3. In the complete case analysis for rural older people, the HR for participation in work and local community was below 1.00, but the statistical significance disappeared. Further, the results of the complete case analysis for urban older people, excluding patients missing any of the variables used in the analysis, were similar to those when the "missing" category was used in the analysis, to account for missing responses to questions. The full modeling results in Model 2 were presented in Table S4. The result of the social networks, such as emotional support, instrumental support, and frequency of meeting friends, added in Model 2, was similar to the analysis of the number of organizations.

\section{Discussion}

To the best of our knowledge, this is the first longitudinal study to compare the relationship between the number and type of organizations, including work, and incidence of functional decline in rural and urban areas separately.

In all, two findings were obtained from this study: (1) a "dose-response" relationship was seen both among rural and urban areas, with progressively lower HRs as the number of different types of 
organizations increased; and (2) participation in sports, hobbies, and work were protective against incidences of decline in both rural and urban areas. In this study the classification of rural and urban areas is as proposed by the OECD. Previous studies have used population density and national classification; however this study adopted an international classification system. Even when classifying areas by population density, the results of this study were almost the same.

The analysis of the number of organizations revealed the HRs of the number of types of organizations progressively decreased as the number of participating organizations. This supports previous studies, including those measuring other health outcomes $[10,13,16-18]$. In this study, HRs were lower when participated in two or more types of organizations in rural areas than in urban areas. The social relationships specific to rural areas may be the reason why older people living in these areas need to join more than one organization. Previous studies have indicated that bonding social capital comprising a connection between community members is often stronger among rural older adults, resulting in community strength $[27,28]$. In this study, participation in local community organizations was higher in rural areas than in urban areas. However, excessive bonding social capital tends to have negative effects [35]. According to the systematic review of the negative health effects of social capital [35], there are downsides to social capital that emerge in the context of strong bonding social capital, but not in weak bridging social capital. (1) Strong bonding ties impose heavy obligations on community members by following a dominant social hierarchy and social norms, and it exclude outsiders. (2) The lack of bridging SC is crucial in socioeconomically disadvantaged communities. (3) In such settings, the connection of members to outside sources of support is even more important. In closed communities, such as those in rural areas, participation in more organizations may improve bridging social capital. For the above reasons, older people in rural areas may benefit from participation in a greater number of organizations.

Many types of organizational participation were protective against functional decline in Model 1, which included factors such as age, equivalent income, educational attainment, marital status, and self-reported medical conditions. However, in Model 2, factors such as behavioral, psychosocial, and functional confounders, as well as participation in sports, hobbies, and work, were protective against incidences of decline.

This is the first longitudinal study to compare work with other community organizations by defining work as a type of social participation. Previous longitudinal studies focusing on the relationship between work and health outcomes among older people have examined work alone [20,36,37], and comparisons with other community organizations have been cross-sectional studies [38]. Given the current challenges posed by a rapidly declining birthrate and aging population, it is necessary to develop a social structure where many older people work [39]. Working support for older people is expected to contribute not only to a substantial increase in the labor force but also to a decrease in the number of older people requiring care [39]. This study showed that working support and improvement of working environment could be public health policies that would prevent the need for the provision of long-term care in rural and urban areas. In longitudinal studies of work and health outcomes [20,36,37], work is generally considered good for health. However, poor-quality work [36] is not good for health; therefore, additional analysis is necessary, since this research did not consider the type of work.

The results indicating that participation in sports and hobby groups were protective against disability were similar to previous studies [10]. According to this result, a good public health policy would include local government provision of regular opportunities for social participation in sports and hobbies in both rural and urban areas. Participation in sports and hobby groups has also been reported to prevent other poor health outcomes $[16,18,19]$. Previous studies have shown that older people in rural areas were unhealthier than older people in urban areas $[20,24,29,30]$, but in this study, there was no difference in the incidence of functional disability between older people in rural and urban areas. The reason may be that there was no difference in the urban-rural participation rates in sports and hobby groups among the participants of this study. Even in rural areas, promoting 
participation in groups such as sports and hobbies groups could prevent the incidence of functional decline. In Japan, the salon-type community intervention [40] has been implemented as one of the ways to promote social participation. These salons, managed by local volunteers, are held once or twice a month in communal spaces within walking distance of community members' homes, and older people can meet and interact with others through enjoyable, relaxing, and sometimes educational programs [40]. Moreover, participation in local community organizations was only protective against decline in rural older people in this study. In the scoping review by Carver et al. [41], older people who lived in rural areas had many opportunities to engage in community-association activities, and through such social participation, a sense of belonging was created. They suggested that such social participation is important for achieving successful aging in rural areas.

The preventive effects against functional decline of the number and types of social participation were almost the same among both rural and urban areas in this study. Quite a few studies on age-friendly cities showed that urban areas are suitable for active aging [42]. One of the reasons for that may be a larger quantity of amenities and possibilities for social interactions/organizations and easier access to those in urban areas compared to rural areas. It could be an effective intervention that older people move to urban areas when their health/physical ability starts to decline. Nowadays, the compact city, i.e., located in the rural city center, but short-distance from urban functions, trials have begun in Japan $[43,44]$, and their effectiveness is expected to be verified.

This study has two strengths. First, this is the first study to target older people in many municipalities, including rural and urban areas, in contrast to previous studies that only focused on the number and type of organization in which older people participated $[10,13,16-18]$. Second, the data used in this study was collected over a long period (about six years) and excluded respondents receiving long-term care within two years, thereby removing the possibility of reverse causality (i.e., the possibility that people who had a high risk of functional decline did not participate socially).

This study had three limitations. First, we did not consider the frequency of social participation. It has been reported that the relationship between social participation and health outcomes differs depending on the frequency of social participation $[16,18,38]$. However, this research emphasized a comparison between rural and urban areas in line with a previous study [10]. Second, we did not consider the older people's role of the organization they participated in, such as being a member or a leader. A leading role in an organization has an additional effect on social participation and health outcomes [15,45]. Finally, this study only focuses on the differences between rural and urban areas; however, there may be other environmental characteristics to consider. The NuAge Study showed environmental factors associated with social participation of older people vary by living areas, such as metropolitan, urban, and rural areas [29]. In Japan, it was reported that environmental factors such as access to facilities, shops, and parks and sidewalks were related to participation in sports groups [46]. Future longitudinal or interventional studies focusing on rural and urban environmental improvement will be needed.

\section{Conclusions}

We compared the relationship between social participation, including work and incidence of functional decline in rural and urban older people, to inform public health policies that would prevent functional decline in older individuals residing in Japan. Participating in various organizations protected older people from functional decline, and, thus, it might be essential to facilitate the benefits of such participation to both rural and urban older people. Furthermore, participation in sports, hobbies, and work was protective against incidences of decline in both rural and urban regions. For both rural and urban older people, promoting social participation, such as sports and hobbies groups and employment support, seems to be an important aspect of public health policies that would prevent functional decline. 
Supplementary Materials: The following are available online at http://www.mdpi.com/1660-4601/17/2/617/s1, Table S1: Complete case analysis: HRs for participation in one, two, and three or more different types of organizations, Table S2: The full modeling results for participation in one, two, and three or more different types of organizations in Model 2, Table S3: Complete case analysis: HRs for type of social participation (reference: nonparticipation in each organization), Table S4: The full modeling results for HRs for type of social participation (reference: nonparticipation in each organization).

Author Contributions: Conceptualization and methodology, K.I., T.T., and S.K.; validation, K.I. and T.T.; formal analysis, K.I.; data curation, T.T.; writing—original draft preparation, K.I.; writing-review and editing, T.T. and S.K.; supervision, S.J., Y.N., and K.K.; project administration, K.K. All authors have read and agreed to the published version of the manuscript.

Funding: This study used data from JAGES (the Japan Gerontological Evaluation Study). This study was supported by Grant-in-Aid for Scientific Research (15H01972, 15H04781, 15H05059, 15K03417, 15K03982, 15K16181, 15K17232, 15K18174, 15K19241, 15K21266, 15KT0007, 15KT0097, 16H05556, 16K09122, 16K00913, 16K02025, 16K12964, 16K13443, 16K16295, 16K16595, 16K16633, 16K17256, 16K17281, 16K19247, 16K19267, 16K21461, 16K21465, 16KT0014, 17K04305, 17K34567, 17K04306, 25253052, 25713027, 26285138, 26460828, 26780328, 18H03018, 18H04071, 18H03047, 18H00953, 18H00955, 18KK0057, 18074040, 19H03901, 19H03915, 19H03860, 19K04785, 19K10641, 19K11657, 19K19818, 19K19455, 19K24060, 19K20909) from JSPS (Japan Society for the Promotion of Science); Health Labour Sciences Research Grants (H26-Choju-Ippan-006, H27-Ninchisyou-Ippan-001 H28-Choju-Ippan-002, H28-Ninchisyou-Ippan-002, H29-Chikyukibo-Ippan-001, H30-Jyunkankinado-Ippan-004, 18H04071, 19FA1012, 19FA2001) from the Ministry of Health, Labour and Welfare, Japan; the Research and Development Grants for Longevity Science from Japan Agency for Medical Research and development (AMED) (JP17dk0110027, JP18dk0110027, JP181s0110002, JP18le0110009, JP19dk0110034, JP19dk0110037), the Research Funding for Longevity Sciences from National Center for Geriatrics and Gerontology (24-17, 24-23, 29-42, 30-30, 30-22); Open Innovation Platform with Enterprises, Research Institute and Academia (OPERA, JPMJOP1831) from the Japan Science and Technology (JST); a grant from the Japan Foundation For Aging And Health (J09KF00804), a grant from Innovative Research Program on Suicide Countermeasures (1-4), a grant from Sasakawa Sports Foundation, a grant from Japan Health Promotion \& Fitness Foundation, a grant from Chiba Foundation for Health Promotion \& Disease Prevention, the 8020 Research Grant for fiscal 2019 from the 8020 Promotion Foundation (adopted number: 19-2-06), a grant from Niimi University (1915010), grants from Meiji Yasuda Life Foundation of Health and Welfare. The views and opinions expressed in this article are those of the authors and do not necessarily reflect the official policy or position of the respective funding organizations.

Acknowledgments: We would like to thank the study participants. We would also like to thank Hanazato (Chiba University) for teaching us the classification of rural and urban settings.

Conflicts of Interest: The authors declare no conflicts of interest.

\section{References}

1. Kalache, A.; Kickbusch, I. A global strategy for healthy ageing. World Health 1997, 50, 2.

2. Walker, A. A strategy for active ageing. Int. Soc. Secur. Rev. 2002, 55, 121-139. [CrossRef]

3. Active Age Consortium. Vercoming the barriers and seizing the opportunities for active ageing policies in Europe. Int. Soc. Sci. J. 2016, 58, 617-631.

4. UNECE. 2018 Active Ageing Index: Analytical Report. Available online: https:/www.unece.org/fileadmin/ DAM/pau/age/Active_Ageing_Index/Stakeholder_Meeting/ACTIVE_AGEING_INDEX_TRENDS_20082016_web_cover_reduced.pdf (accessed on 28 December 2019).

5. Zaidi, A.; Gasior, K.; Hofmarcher, M.M.; Lelkes, O.; Marin, B.; Rodrigues, R.; Schmidt, A.; Vanhuysse, P.; Zolyomi, E. Active Ageing Index 2012: Concept, Methodology and Final Results', Methodology Report Submitted to European Commission's DG Employment, Social Affairs and Inclusion, and to Population Unit, UNECE, for the Project: 'Active Ageing Index (AAI)', UNECE Grant No: ECE/GC/2012/003, Geneva; European Centre Vienna: Wien, Austria, 2013.

6. Douglas, H.; Georgiou, A.; Westbrook, J. Social participation as an indicator of successful aging: An overview of concepts and their associations with health. Aust. Health Rev. 2017, 41, 455-462. [CrossRef] [PubMed]

7. WHO. Active Ageing: A Policy Framework. Available online: https://apps.who.int/iris/bitstream/handle/ 10665/67215/WHO_NMH_NPH_02.8.pdf (accessed on 27 August 2019).

8. WHO. Global Age-Friendly Cities: A Guide. Available online: https://www.who.int/ageing/publications/ Global_age_friendly_cities_Guide_English.pdf (accessed on 27 August 2019).

9. Aida, J.; Kondo, K.; Kawachi, I.; Subramanian, S.V.; Ichida, Y.; Hirai, H.; Kondo, N.; Osaka, K.; Sheiham, A.; Tsakos, G.; et al. Does social capital affect the incidence of functional disability in older Japanese? A prospective population-based cohort study. J. Epidemiol. Community Health 2013, 67, 42-47. [CrossRef] [PubMed] 
10. Kanamori, S.; Kai, Y.; Aida, J.; Kondo, K.; Kawachi, I.; Hirai, H.; Shirai, K.; Ishikawa, Y.; Suzuki, K.; JAGES Group. Social participation and the prevention of functional disability in older Japanese: The JAGES cohort study. PLoS ONE 2014, 9, e99638. [CrossRef]

11. Hikichi, H.; Kondo, N.; Kondo, K.; Aida, J.; Takeda, T.; Kawachi, I. Effect of a community intervention programme promoting social interactions on functional disability prevention for older adults: Propensity score matching and instrumental variable analyses, JAGES Taketoyo study. J. Epidemiol. Community Health 2015, 69, 905-910. [CrossRef]

12. Otsuka, T.; Tomata, Y.; Zhang, S.; Sugiyama, K.; Tanji, F.; Sugawara, Y.; Tsuji, I. Association between social participation and incident risk of functional disability in older people Japanese: The Ohsaki Cohort 2006. J. Psychosom. Res. 2018, 111, 36-41. [CrossRef]

13. Gao, M.; Sa, Z.; Li, Y.; Zhang, W.; Tian, D.; Zhang, S.; Gu, L. Does social participation reduce the risk of functional disability among older adults in China? A survival analysis using the 2005-2011 waves of the CLHLS data. BMC Geriatr. 2018, 18, 224. [CrossRef]

14. Hikichi, H.; Kondo, K.; Takeda, T.; Kawachi, I. Social interaction and cognitive decline: Results of a 7-year community intervention. Alzheimers Dement. (N. Y.) 2016, 3, 23-32. [CrossRef]

15. Nemoto, Y.; Saito, T.; Kanamori, S.; Tsuji, T.; Shirai, K.; Kikuchi, H.; Maruo, K.; Arao, T.; Kondo, K. An additive effect of leading role in the organization between social participation and dementia onset among Japanese older adults: The AGES cohort study. BMC Geriatr. 2017, 17, 297. [CrossRef] [PubMed]

16. Tomioka, K.; Kurumatani, N.; Hosoi,H. Social participation and cognitive decline among community-dwelling older adults: A community-based longitudinal study. J. Gerontol. B Psychol. Sci. Soc. Sci. 2018, 73, 799-806. [CrossRef] [PubMed]

17. Nonaka, K.; Suzuki, H.; Murayama, H.; Hasebe, M.; Koike, T.; Kobayashi, E.; Fujiwara, Y. For how many days and what types of group activities should older Japanese adults be involved in to maintain health? A 4-year longitudinal study. PLoS ONE 2017, 12, e0183829. [CrossRef] [PubMed]

18. Tomioka, K.; Kurumatani, N.; Saeki, K. The differential effects of type and frequency of social participation on IADL declines of older people. PLoS ONE 2018, 13, e0207426. [CrossRef]

19. Fujihara, S.; Tsuji, T.; Miyaguni, Y.; Aida, J.; Saito, M.; Koyama, S.; Kondo, K. Does Community-Level Social Capital Predict Decline in Instrumental Activities of Daily Living? A JAGES Prospective Cohort Study. Int. J. Environ. Res. Public Health 2019, 16, 828. [CrossRef]

20. Fujiwara, Y.; Shinkai, S.; Kobayashi, E.; Minami, U.; Suzuki, H.; Yoshida, H.; Ishizaki, T.; Kumagai, S.; Watanabe, S.; Furuna, T.; et al. Engagement in paid work as a protective predictor of basic activities of daily living disability in Japanese urban and rural community-dwelling older people residents: An 8-year prospective study. Geriatr. Gerontol. Int. 2016, 16, 126-134. [CrossRef]

21. Organization for Economic Co-Operation and Development. Scoreboard on Older Workers, 2006 and 2016. Available online: http://www.oecd.org/els/emp/older-workers-scoreboard-2016.xlsx (accessed on 27 August 2019).

22. Organization for Economic Co-Operation and Development. Recommendation of the Council on Ageing and Employment Policies. Available online: http://www.oecd.org/els/emp/Ageing-Recommendation.pdf (accessed on 27 August 2019).

23. Guo, Q.; Bai, X.; Feng, N. Social participation and depressive symptoms among Chinese older adults: A study on rural-urban differences. J. Affect. Disord. 2018, 239, 124-130. [CrossRef]

24. Yoshimura, N.; Akune, T.; Fujiwara, S.; Shimizu, Y.; Yoshida, H.; Nishiwaki, Y.; Sudo, A.; Omori, G.; Yoshida, M.; Shimokata, H.; et al. Incidence of disability and its associated factors in Japanese men and women: The Longitudinal Cohorts of Motor System Organ (LOCOMO) study. J. Bone Miner. Metab. 2015, 33, 186-191. [CrossRef]

25. Singh, G.K.; Siahpush, M. Widening rural-urban disparities in life expectancy, U.S., 1969-2009. Am. J. Prev. Med. 2014, 46, e19-e29. [CrossRef]

26. Vogelsang, E.M. Older adult social participation and its relationship with health: Rural-urban differences. Health Place 2016, 42, 111-119. [CrossRef]

27. He, Q.; Cui, Y.; Liang, L.; Zhong, Q.; Li, J.; Li, Y.; Lv, X.; Huang, F. Social participation, willingness and quality of life: A population-based study among older adults in rural areas of China. Geriatr. Gerontol. Int. 2017, 17, 1593-1602. [CrossRef] [PubMed] 
28. Winterton, R. Organizational responsibility for age-friendly social participation: Views of Australian rural community stakeholders. J. Aging Soc. Policy 2016, 28, 261-276. [CrossRef] [PubMed]

29. Levasseur, M.; Cohen, A.A.; Dubois, M.F.; Généreux, M.; Richard, L.; Therrien, F.H.; Payette, H. Environmental factors associated with social participation of older adults living in metropolitan, urban, and rural areas: The NuAge Study. Am. J. Public Health 2015, 105, 1718-1725. [CrossRef] [PubMed]

30. Tobiasz-Adamczyk, B.; Zawisza, K. Urban-rural differences in social capital in relation to self-rated health and subjective well-being in older residents of six regions in Poland. Ann. Agric. Environ. Med. 2017, 24, 162-170. [CrossRef]

31. Kondo, K. Progress in aging epidemiology in Japan: The JAGES Project. J. Epidemiol. 2016, 26, 331-336. [CrossRef]

32. Kondo, K.; Rosenberg, M.; World Health Organization. Advancing Universal Health Coverage through Knowledge Translation for Healthy Ageing: Lessons Learnt from the Japan Gerontological Evaluation Study; World Health Organization: Geneva, Switzerland, 2018.

33. Tsutsui, T.; Muramatsu, N. Care-needs certification in the long-term care insurance system of Japan. J. Am. Geriatr. Soc. 2005, 53, 522-527. [CrossRef]

34. OECD. Definition of Functional Urban Areas (FUA) for the OECD Metropolitan Database. Available online: https://www.oecd.org/cfe/regional-policy/Definition-of-Functional-Urban-Areas-for-the-OECDmetropolitan-database.pdf (accessed on 27 August 2019).

35. Villalonga-Olives, E.; Kawachi, I. The dark side of social capital: A systematic review of the negative health effects of social capital. Soc. Sci. Med. 2017, 194, 105-127. [CrossRef]

36. Welsh, J.; Strazdins, L.; Charlesworth, S.; Kulik, C.T.; Butterworth, P. Health or harm? A cohort study of the importance of job quality in extended workforce participation by older adults. BMC Public Health 2016, 16, 885. [CrossRef]

37. Minami, U.; Nishi, M.; Fukaya, T.; Hasebe, M.; Nonaka, K.; Koike, T.; Suzuki, H.; Murayama, Y.; Uchida, H.; Fujiwara, Y. Effects of the Change in Working Status on the Health of Older People in Japan. PLoS ONE 2015, 10, e0144069. [CrossRef]

38. Tomioka, K.; Kurumatani, N.; Hosoi, H. Age and gender differences in the association between social participation and instrumental activities of daily living among community-dwelling older people. BMC Geriatr. 2017, 17, 99. [CrossRef]

39. Arai, H.; Ouchi, Y.; Yokode, M.; Ito, H.; Uematsu, H.; Eto, F.; Oshima, S.; Ota, K.; Saito, Y.; Sasaki, H.; et al. Toward the realization of a better aged society: Messages from gerontology and geriatrics. Geriatr. Gerontol. Int. 2012, 12, 16-22. [CrossRef] [PubMed]

40. Saito, J.; Haseda, M.; Amemiya, A.; Takagi, D.; Kondo, K.; Kondo, N. Community-based care for healthy ageing: Lessons from Japan. Bull. World Health Organ. 2019, 97, 570-574. [CrossRef] [PubMed]

41. Carver, L.; Beamish, R.; Phillips, S.; Villeneuve, M. A Scoping Review: Social Participation as a Cornerstone of Successful Aging in Place among Rural Older Adults. Geriatrics (Basel) 2018, 3, 75. [CrossRef] [PubMed]

42. Noordzij, J.M.; Beenackers, M.A.; Diez Roux, A.V.; van Lenthea, F.J. Age-friendly cities: Challenges for future research. Bull. World Health Organ. 2019, 97, 436-437. [CrossRef]

43. Toyama City. Sustainable Compact City Strategy Responding to the Declining and Super-Ageing Population: Compact City Planning through the Renovation of Public Transportation. Available online: http://www.clair. or.jp/e/2016-4-1Toyama\%20City.pdf (accessed on 28 December 2019).

44. Ministry of Land, Infrastructure, Transport and Tourism. Promotion of Urban Renovation and Compact Cities. Available online: https://www.mlit.go.jp/common/000996976.pdf (accessed on 28 December 2019).

45. Takagi, D.; Kondo, K.; Kawachi, I. Social participation and mental health: Moderating effects of gender, social role and rurality. BMC Public Health 2013, 13, 701. [CrossRef]

46. Yamakita, M.; Kanamori, S.; Kondo, N.; Kondo, K. Correlates of Regular Participation in Sports Groups among Japanese Older Adults: JAGES Cross-Sectional Study. PLoS ONE 2015, 10, e0141638. [CrossRef]

(C) 2020 by the authors. Licensee MDPI, Basel, Switzerland. This article is an open access article distributed under the terms and conditions of the Creative Commons Attribution (CC BY) license (http://creativecommons.org/licenses/by/4.0/). 